\title{
AEROSOL CYCLOSPORINE PREVENTS ACUTE ALLOGRAFT REJECTION IN EXPERIMENTAL LUNG TRANSPLANTATION
}

\author{
Surindra N. Mitruka, MD \\ Si M. Pham, MD \\ Adriana Zeevi, $\mathrm{PhD}^{\mathrm{a}}$ \\ Sen Li, MD \\ Jane Cai, MD \\ Gilbert J. Burckart, PharmD ${ }^{\mathrm{b}}$ \\ Samuel A. Yousem, $\mathrm{MD}^{\mathrm{c}}$ \\ Robert J. Keenan, MD ${ }^{a}$ \\ Bartley P. Griffith, MD
}

Background: The incidence of acute rejection and the morbidity of systemic cyclosporine (INN: ciclosporin) after lung transplantation is significant. Experimental evidence suggests that the allograft locally modulates the immune mechanisms of acute rejection. The purpose of this study was to determine whether aerosolized cyclosporine would prevent acute cellular rejection, achieve effective graft concentrations with low systemic drug delivery, and locally affect production of the inflammatory cytokines involved in acute rejection. Methods: Unilateral orthotopic left lung transplantation was performed in 64 rats (ACI to Lewis), which were divided into eight groups (each group, $n=8$ ): group $A$, no treatment; groups $B$ to $D$, aerosol cyclosporine 1 to $3 \mathrm{mg} / \mathrm{kg}$ per day, respectively; groups $\mathrm{E}$ to $\mathrm{H}$, systemic cyclosporine 2, 5, 10, and $15 \mathrm{mg} / \mathrm{kg}$ per day, respectively. After the animals were killed on postoperative day 2,4 , or 6 , the transplanted lung, native lung, spleen, and blood were collected. Histologic studies, highpressure liquid chromatography for trough cyclosporine concentrations, and reverse-transcriptase polymerase chain reaction for cytokine gene expression were performed. Results: Untreated animals showed grade 4 rejection by postoperative day 6. Aerosol cyclosporine prevented acute rejection in a dose-dependent fashion, with group D animals $(3 \mathrm{mg} / \mathrm{kg}$ per day) showing minimal grade 1 changes. Among animals receiving systemic cyclosporine, only group H (15 mg/kg per day) controlled (grade 1) rejection. However, aerosol cyclosporine, at an $\mathbf{8 0 \%}$ lower dose, achieved significantly lower concentrations of cyclosporine in the graft $(12,349 \mathrm{vs}$ 28,714 ng/mg, $p=0.002004$ ) and blood (725 vs $3306 \mathrm{ng} / \mathrm{ml}, p=0.000378$ ). Group F (systemic $5 \mathrm{mg} / \mathrm{kg}$ per day) had higher cyclosporine concentrations in the blood than group $D(p=\mathbf{0 . 0 0 4 5 7 2})$ and similar tissue concentrations $(p=0.115180)$, yet had grade 2 rejection. Reverse-transcriptase polymerase chain reaction demonstrated equivalent suppression of inducible nitric oxide synthase but a 20- to 25-fold higher expression of interleukin-6, interleukin-10, and interferon- $\gamma$ in group $D$ versus group $H$ recipient allografts. Conclusion: Local delivery of cyclosporine by aerosol inhalation dose-dependently prevented acute pulmonary allograft rejection. Effective graft levels and low systemic drug delivery required significantly lower doses than systemic therapy alone. The gene expression of proinflammatory cytokines involved in allograft rejection was suppressed by aerosol cyclosporine therapy. (J Thorac Cardiovasc Surg 1998;115:28-37)
From the Departments of Cardiothoracic Surgery, ${ }^{\text {a }}$ Clinical Pharmacology, ${ }^{\mathrm{b}}$ and Pathology, ${ }^{\mathrm{c}}$ University of Pittsburgh School of Medicine, Pittsburgh, Pa.

This research has been supported by National Institutes of Health grant RO1-HL48091-03.

Read at the Seventy-seventh Annual Meeting of The American Association for Thoracic Surgery, Washington, D.C., May 4-7, 1997.
Received for publication May 7, 1997; revisions requested June 16, 1997; revisions received Sept. 8, 1997; accepted for publication Sept. 9, 1997.

Address for reprints: Bartley P. Griffith, MD, Professor of Surgery, Chief, Cardiothoracic Surgery, University of Pittsburgh School of Medicine Suite C-700 PUH, 200 Lothrop St., Pittsburgh, PA 15261.

Copyright (C) 1998 by Mosby, Inc.

$0022-5223 / 98 \$ 5.00+0 \quad \mathbf{1 2} / \mathbf{6} / \mathbf{8 6 3 6 2}$ 
P ulmonary transplantation is an accepted and established therapeutic option for a variety of end-stage lung diseases. ${ }^{1}$ Despite the initiation of systemic immunosuppression with cyclosporine (INN: ciclosporin) or tacrolimus-based triple drug therapy shortly after implantation, acute cellular rejection occurs frequently, with an incidence approaching $90 \%$ in our transplant population. ${ }^{2}$ Increasing evidence suggests that the acute rejection process is initiated and modulated locally within the allograft. Alloactivation by major histocompatibility complex (MHC) antigens on passenger leukocytes in the graft provokes an intense inflammatory reaction resulting in a rapid influx of neutrophils and macrophages. The subsequent release of cytokines and nitric oxide promotes local macrophage amplification and donor-specific $\mathrm{T}$ - and B-cell clonal expansion.

Episodes of acute cellular rejection are usually managed with pulse corticosteroids or cytolytic therapy. These efforts are not uniformly successful, and persistent acute rejection develops in many recipients. ${ }^{3}$ Aside from the inflammatory reaction causing pulmonary tissue damage, the two major sequelae of acute rejection are the limiting factors to successful lung transplantation today. First, the end-organ toxicity from continued systemic immunosuppression is well recognized. The incidence of infections, nephrotoxicity, diabetes, hypertension, and solid organ tumors is significant in the transplant population. ${ }^{4}$ Second, acute rejection may be the predominant risk factor for the development of obliterative bronchiolitis. 5

It is presumed that systemic immunosuppression incurs a delay in achieving appropriate allograft drug levels, thereby permitting the local inflammatory response to begin. It is conceivable, therefore, that acute rejection could be prevented if the activation of antigen-presenting cells and the maturation and proliferation of effector cells was arrested by the early administration of immunosuppressive agents directly into the allograft. Aerosol cyclosporine represents an alternative drug delivery system that may be ideal in achieving this goal.

Regional immunosuppression is predicated on two basic concepts. First, controlling the early intragraft immune events will prevent acute rejection. Second, obtaining high local drug delivery with low systemic drug delivery will diminish the adverse consequences of systemic immunosuppression. Local cyclosporine, tacrolimus, and steroid therapy have been used in numerous experimental models of heart, liver, and kidney ${ }^{6-9}$ transplantation. These studies have reported promising results in controlling rejection and achieving low systemic drug delivery. However, many of these models have used drug delivery systems that make widespread clinical application unlikely. Lung transplantation offers a unique opportunity to study the efficacy of local immunosuppression because of the ease with which airborne drugs may be deposited in the allograft by inhalation. Our group has previously demonstrated the efficacy of aerosol cyclosporine in canine ${ }^{10}$ and rodent ${ }^{11,12}$ models with a variety of aerosol and systemic cyclosporine doses. Recent modification of an efficient and commercially available aerosol delivery system, new data altering the calculated intrapulmonary deposition of cyclosporine, and the widespread availability of molecular techniques have prompted us to explore the applicability of aerosol cyclosporine in controlling acute rejection in a rodent lung transplant model. The objective of this experiment was to determine whether aerosol cyclosporine as locoregional monotherapy would prevent acute cellular rejection, achieve effective allograft and low systemic drug delivery, and locally attenuate the inflammatory cytokines associated with acute rejection.

\section{Materials and methods}

Animals. ACI and Lewis rats, 4 to 8 weeks old, were purchased from Harlan Sprague Dawley (Indianapolis, Ind.). The animals were housed in a specific pathogenfree facility at the University of Pittsburgh Bioscience Tower. All animals received humane care in compliance with the "Principles of Laboratory Animal Care" formulated by the National Society for Medical Research and the "Guide for the Care and Use of Laboratory Animals" prepared by the National Academy of Sciences and published by the National Institutes of Health (NIH Publication No. 86-23, revised 1985).

Lung transplantation. Unilateral orthotopic left lung transplantation across $\mathrm{MHC}$ and minor antigen disparate species ${ }^{13}$ was performed with ACI rats used as donors and Lewis rats, weighing 225 to $275 \mathrm{gm}$, as recipients. Allografts were transplanted by the cuff technique as previously described. ${ }^{12,14} \mathrm{Graft}$ cold ischemic time in $40^{\circ} \mathrm{C}$ heparinized lactated Ringer's solution ranged from 20 to 40 minutes. No antibiotic prophylaxis was administered after the operation.

Experimental groups and specimen collection. Recipients were divided into eight experimental groups. Group A $(n=8)$ animals served as controls and received no immunosuppression. Group B, C, and D animals (each group, $n=8$ ) received aerosol cyclosporine in dosages of 1,2 , and $3 \mathrm{mg} / \mathrm{kg}$ per day, respectively. Group E, F, G, and $\mathrm{H}$ animals (each group, $n=8$ ) received systemic cyclosporine/polyoxyl castor oil (Cremophore) dissolved in 
saline solution by subcutaneous injection in dosages of 2 , 5,10 , and $15 \mathrm{mg} / \mathrm{kg}$ per day, respectively. All animals received the first assigned cyclosporine dose within 1 hour of transplantation on postoperative day (POD) 0 . The same dose was dispensed every 24 hours until the animal was killed on POD 2, 4, or 6. The last cyclosporine dose was administered 24 hours before the animal was put to death, and the specimens were harvested immediately thereafter. All recipients were killed by inhalation of methoxyflurane, followed by exsanguination via direct cardiac puncture. Whole blood was collected in ethylenediaminetetraacetic acid Vacutainer $2.5 \mathrm{ml}$ tubes (Becton Dickinson, Franklin Lakes, N.J.). The allograft, native lung, and spleen were cryopreserved by immersion in liquid nitrogen after placement in $1.7 \mathrm{ml}$ sterile microcentrifuge tubes (VWR Scientific, Bridgeport, N.J.).

Aerosol generation. Cyclosporine powder (a generous gift from Sandoz Pharmaceuticals Inc., Basel, Switzerland) was dissolved in $100 \%$ ethanol to a final concentration of $40 \mathrm{mg} / \mathrm{ml}$. The cyclosporine/ethanol solution was delivered to the commercially available Aero-Tech II Nebulizer (CIS-US, Inc., Bedford, Mass.) at a rate of 1 $\mathrm{ml} / \mathrm{min}$. A compressed-air driving pressure of $80 \mathrm{psi}$ with entrained room air resulted in a chamber flow rate of 13.9 $\mathrm{L} / \mathrm{min}$, generating an aerosol mist with a mass median aerodynamic equivalent of 0.7 to $1.2 \mu \mathrm{m}$ in diameter with a geometric standard deviation of $1.6 \mu \mathrm{m}$. The aerosol exposure chamber (Lovelace Inhalation and Toxicology Research Institute [ITRI], Albuquerque, N.M.) is a 24port laminar flow chamber with individual nosepieces that allows simultaneous exposure to multiple animals.

The airborne concentration of cyclosporine in the chamber was determined by continuously drawing air samples at a rate of $0.534 \mathrm{~L} / \mathrm{min}$ onto $47 \mathrm{~mm} 0.5 \mu \mathrm{m}$ polytetrafluoroethylene filters (Millipore, Bedford, Mass.). Gravimetric analysis was conducted on the filter sample to determine the amount (in milligrams) of deposited cyclosporine. The time necessary per exposure to achieve the desired intrapulmonary deposition of cyclosporine was calculated on the basis of a modification of the Alarie formula. ${ }^{15}$ The chamber-air concentration of cyclosporine in milligrams per liter (amount of deposited cyclosporine per filter in milligrams $\div 0.534 \mathrm{~L} / \mathrm{min} \times$ number of minutes per sampling) $\times 0.25 \mathrm{~L} / \mathrm{min}$ (rat minute ventilation $) \times 0.1(10 \%=$ efficiency of deposition $)^{16}$ (personal communication from ITRI) yielded the anticipated intrapulmonary deposition of cyclosporine in milligrams per minute. The animal's weight (in kilograms) times the desired dose (in milligrams per kilogram per day) divided by the intrapulmonary deposition (in milligrams per minute) yielded the number of minutes necessary to achieve the desired dose of cyclosporine by aerosol inhalation. Thus the only variable to alter the desired delivered cyclosporine dose was exposure time.

Ethanol vapor concentration has previously ${ }^{12}$ approximated 3000 to $5000 \mathrm{ppm}$ during sham exposures. From prior toxicologic studies ${ }^{11}$ (personal communication from ITRI), this level of ethanol vapor exposure has not resulted in toxicity or alterations in rodent pulmonary physiology. Therefore the ethanol vapor concentration in this study was not determined. Oxygen levels within the chamber were continuously monitored by a MiniOX 1 analyzer (MSA Medical Products, Pittsburgh, Pa.) and maintained at approximately $21 \%$.

Histologic analysis. All allografts and native lungs were divided after being harvested and were preserved in $10 \%$ formalin solution (Fisher Scientific, Fair Lawn, N.J.). A medial sagittal pulmonary section was embedded in paraffin, sectioned, stained with hematoxylin and eosin, and blindly graded by a previously reported standardized nomenclature for lung allograft rejection. ${ }^{17}$ In brief, the grading scale is as follows: grade 0 , no cellular infiltrates; grade 1 , perivascular infiltrates of small round and transformed large lymphoid cells and immunoblasts and endotheliolitis (endothelial cell hypertrophy and epithelioid changes); grade 2, perivascular mononuclear infiltrates with spread into adjacent alveolar septae and prominent alveolar macrophages; grade 3 , perivascular mononuclear infiltrate with peribronchiolar inflammation, lymphocyte epidermotropism, epithelial cell and alveolar pneumocyte necrosis, diffuse interstitial pneumonitis, hyaline membranes, and intraalveolar accumulation of neutrophils and macrophages; grade 4, vascular thrombosis with massive intraalveolar hemorrhage and infarction and diffuse interstitial pneumonia with diffuse alveolar damage.

High-pressure liquid chromatography. Whole blood, allograft, native lung, and spleen specimens were assayed by high-pressure liquid chromatography as previously described $^{18}$ to obtain trough cyclosporine levels. The amount of cyclosporine was quantitated with the standard curve of the blood cyclosporine assay, and the tissue concentration was calculated from the tissue weight and initial sample dilution. Levels were expressed as nanograms per milliliter of blood and nanograms per milligram of weighted tissue.

Reverse-transcriptase polymerase chain reaction (RTPCR). First-strand deoxyribonucleic acid (cDNA) was synthesized by transcription from tissue ribonucleic acid (RNA). Oligonucleotides, designed from published sequences of cytokine mRNA, were custom synthesized by the University of Pittsburgh DNA Synthesis facility. The RT-PCR of the cDNA was performed as previously described. ${ }^{19}$ Amplification for the tested cytokines, including interleukin-6 (IL-6), interleukin-10 (IL-10), interferon- $\gamma(\mathrm{INF}-\gamma)$, and inducible nitric oxide synthase (iNOS), was performed for 28 cycles on a model 480 thermal cycler (Perkin Elmer Corp., Norwalk, Conn.). These four cytokines were chosen on the basis of previous studies from our laboratory ${ }^{20}$ demonstrating them to be the most informative in this model of lung allograft rejection. PCR products were analyzed by electrophoresis on $2 \%$ agarose in Tris boric acid ethylenediaminetetraacetic acid, dried on a gel dryer, visualized by ethidium bromide staining, and quantified with a Betagen radioanalytic scanner (Ambis Systems Inc., San Diego, Calif.). The results obtained for each cytokine, in counts per minute, were normalized to cyclophilin and expressed as the mean ratio of mRNA to cyclophilin.

Statistical analysis. Differences in grade of rejection and blood and tissue concentrations between experimental groups was made by one-way analysis of variance with a post hoc analysis by the Bonferroni $t$ test. The Student's unpaired $t$ test was used to determine differences among experimental groups (aerosol vs systemic cyclosporine). 
Table I. Cumulative data for the experimental groups, including treatment, rejection grade, and tissue cyclosporine (CsA) levels

\begin{tabular}{|c|c|c|c|c|c|c|c|}
\hline Group & $N$ & Treatment & Rejection & Blood & Graft & Spleen & $\begin{array}{l}\text { Pulmonary/ } \\
\text { blood ratios }\end{array}$ \\
\hline A & 8 & None & $4 \pm 0$ & 0 & 0 & 0 & \\
\hline B & 8 & $1 \mathrm{mg} / \mathrm{kg}$ aer $\mathrm{CsA}$ & $2.5 \pm 0.5$ & $160 \pm 80$ & $2,564 \pm 1,331$ & $1,244 \pm 1,504$ & 16 \\
\hline $\mathrm{C}$ & 8 & $2 \mathrm{mg} / \mathrm{kg}$ aer $\mathrm{CsA}$ & $2.25 \pm 0.3$ & $265 \pm 99$ & $4,409 \pm 1,496$ & $2,369 \pm 800$ & 16.6 \\
\hline $\mathrm{D}$ & 8 & $3 \mathrm{mg} / \mathrm{kg}$ aer $\mathrm{CsA}$ & $1 \pm 0$ & $725 \pm 222(1)^{*}$ & $12,349 \pm 8,830(2) \dagger$ & $6,043 \pm 3,934$ & 17 \\
\hline $\mathrm{E}$ & 8 & $2 \mathrm{mg} / \mathrm{kg}$ IM CsA & $2.5 \pm 0.4$ & $400 \pm 72$ & $5,861 \pm 3,001$ & $4,324 \pm 1,981$ & 14.7 \\
\hline $\mathrm{F}$ & 8 & $5 \mathrm{mg} / \mathrm{kg}$ IM CsA & $2 \pm 0.4$ & $1,074 \pm 284$ & $15,482 \pm 6,508$ & $11,820 \pm 5,234$ & 14.4 \\
\hline G & 8 & $10 \mathrm{mg} / \mathrm{kg}$ IM CsA & $1.5 \pm 0.6$ & $2,433 \pm 340$ & $18,512 \pm 11,978$ & $15,264 \pm 8,139$ & 7.6 \\
\hline $\mathrm{H}$ & 8 & $15 \mathrm{mg} / \mathrm{kg} \mathrm{IM} \mathrm{CsA}$ & $1 \pm 0.8$ & $3,306 \pm 1,092(4)$ & $28,714 \pm 15,805(5)$ & $25,708 \pm 12,286(6)$ & 8.7 \\
\hline
\end{tabular}

aer, Aerosol; IM, intramuscular; ANOVA, analysis of variance

(1) Group D $<$ groups B $(p=0.000725)$ or C $(p=0.004830)$, ANOVA and Bonferroni $t$ test.

(2) Group D $<$ groups B $(p=0.000444)$ or C $(p=0.001547)$, ANOVA and Bonferroni $t$ test.

(3) Group D $<$ groups B $(p=0.009428)$ or C $(p=0.006217)$, ANOVA and Bonferroni $t$ test.

(4) Group $\mathrm{H}<$ groups E ( $p=0.000023)$, F ( $p$ 0.000748), or G $(p=0.003057)$, ANOVA and Bonferroni $t$ test.

(5) Group H $<$ groups E $(p=0.000776)$, F $(p=0.002512)$, or $\mathrm{G}(p=0.019365)$, ANOVA and Bonferroni $t$ test.

(6) Group $\mathrm{H}<$ groups E $(p=0.000042)$, F $(p=0.000361)$, or $\mathrm{G}(p=0.002865)$, ANOVA and Bonferroni $t$ test.

*Group D $<$ groups H $(p=0.000378)$ and F $(p=0.004572)$, Student's unpaired $t$ test.

$\dagger$ Group D $<$ group H $(p=0.002044)$, but not group F $(p=0.115180)$, Student's unpaired $t$ test.

Exact $p$ values are reported, with a $p$ value of $<0.05$ considered significant. Data are expressed as mean \pm standard deviation.

\section{Results}

Rejection grade and histology. Control recipients (group A), receiving no immunosuppression, exhibited severe destructive grade 4 rejection by POD 6 (Table I). Grossly, the allografts were edematous and necrotic. Histologically, there was obliteration of the alveoli with necrotic debris, interstitial destruction, and vascular thrombosis (Fig. 1, A). The control group differed in rejection grade from all treatment groups (Table I).

Aerosol cyclosporine recipients (groups B, C, and D) exhibited a dose-dependent improvement in rejection grade from $2.5 \pm 0.5$ to $1.0 \pm 0$ (Table I). The most effective aerosol cyclosporine dose was in group D recipients $(3 \mathrm{mg} / \mathrm{kg}$ per day), with these animals displaying mild grade 1 rejection by POD 6 . Grossly, the allografts in these recipients appeared entirely normal; microscopically, there appeared to be minimal cellular interstitial infiltration with perivascular inflammation. The pulmonary architecture and alveolar integrity were preserved (Fig. 1, B).

Recipients of systemic cyclosporine (groups E, F, $\mathrm{G}$, and $\mathrm{H}$ ) also displayed a dose-dependent response in rejection grade from $2.5 \pm 0.4$ to $1.0 \pm 0.8$ (Table I). The most effective cyclosporine dose $(15 \mathrm{mg} / \mathrm{kg}$ per day) also resulted in a mild grade 1 rejection by POD 6. Grossly and microscopically, group H (Fig.
$1, D)$ and group $\mathrm{D}$ recipient allografts appeared similar. It is notable that an equivalent incremental decrease in rejection grade (2.5 to 1.0$)$ required a disproportionate increase in systemic cyclosporine dosing compared with aerosol cyclosporine.

High-pressure liquid chromatography: Blood and tissue cyclosporine levels. All treated animals had measurable cyclosporine levels in blood, allograft, and spleen. The most effective aerosol cyclosporine dose (3 mg/kg per day) achieved cyclosporine levels in the blood and tissue that were significantly different from those measured in groups $\mathrm{B}$ and $\mathrm{C}$ (blood levels, $\mathrm{D}$ vs $\mathrm{B}, p=0.000725$; $\mathrm{D}$ vs $\mathrm{C}, p=0.004830$; tissue levels, $\mathrm{D}$ vs $\mathrm{B}, p=0.000444$; $\mathrm{D}$ vs $\mathrm{C}, p=$ $0.001547)$. The pulmonary/blood ratio of cyclosporine was highest in the group $\mathrm{D}$ animals, with the best rejection control (Table I). These animals had trough graft concentrations of $12,349 \pm 8,830 \mathrm{ng} / \mathrm{mg}$ with blood concentrations of $725 \pm 222 \mathrm{ng} / \mathrm{ml}$, both considered nontoxic by previously published pharmacokinetic and toxicologic studies. ${ }^{21}$ In recipients treated with aerosol cyclosporine, spleen cyclosporine concentrations were significantly lower $(p=$ $0.006608)$ than allograft cyclosporine concentrations.

Significant blood and tissue concentrations of cyclosporine developed in systemically treated animals (Table I). The most effective group $\mathrm{H}$ recipients had blood concentrations of $3306 \pm 1092 \mathrm{ng} / \mathrm{ml}$ and graft concentrations of $28,714 \pm 15,805 \mathrm{ng} / \mathrm{mg}$, both approaching toxicity if maintained over the 

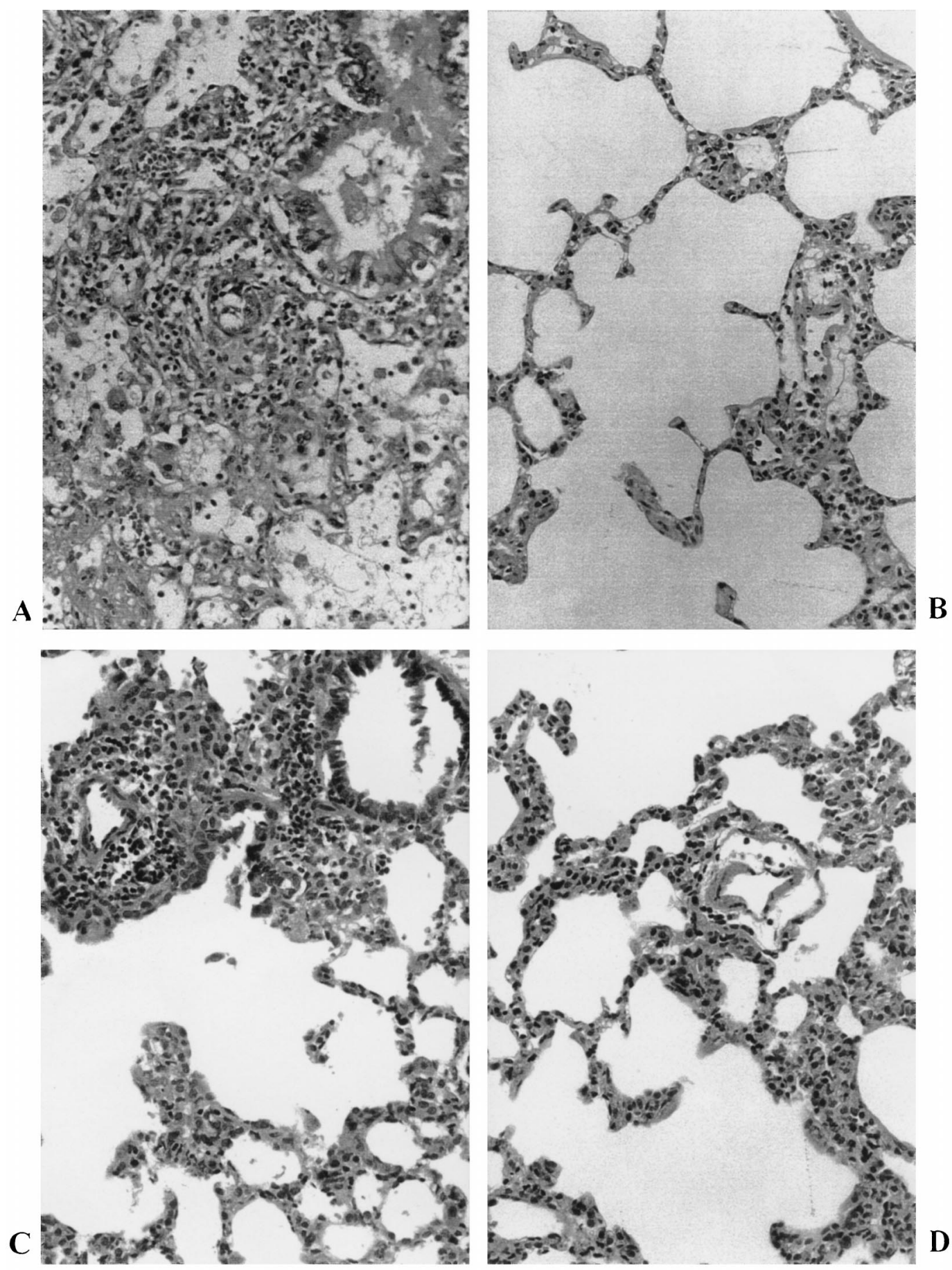

Fig. 1. Histologic studies of untreated animals and those treated with cyclosporine are displayed in the four-panel micrograph at $20 \times$ magnification. A, An untreated allograft on POD 6 with grade 4 rejection. B, An animal from group D ( $3 \mathrm{mg} / \mathrm{kg}$ per day) with grade 1 rejection. There is remarkable preservation of the pulmonary architecture with intact air spaces and a mild inflammatory cellular accumulation in the interstitium. C, An animal from group F ( $5 \mathrm{mg} / \mathrm{kg}$ per day) with a rejection grade of 2 . There is some destruction of the intraalveolar membranes with distortion of the normal pulmonary architecture. D, Histologic study from a group $\mathrm{H}$ recipient $(15 \mathrm{mg} / \mathrm{kg}$ per day) with grade 1 rejection. The overall appearance is similar to that of the aerosol cyclosporine recipient. 


\section{cyclophilin}

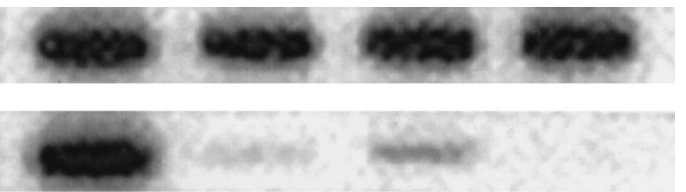

IL-10

IFN- $\gamma$

iNOS
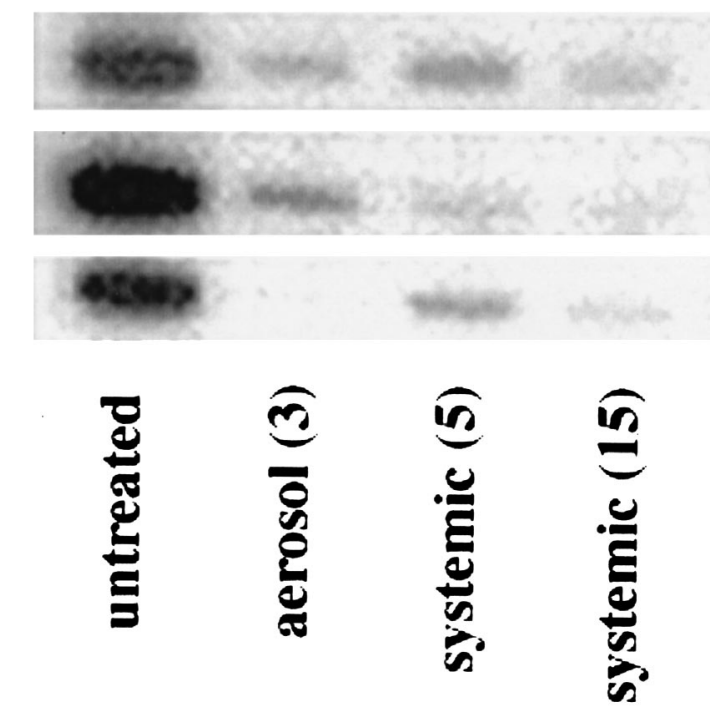

Fig. 2. RT-PCR semiquantitative PCR gel of cytokine and iNOS gene expression within the allograft on POD 6. The control, aerosol (group D), and systemic (groups F and H) groups are represented. There is equivalent attenuation of iNOS in groups D and H by POD 6, but greater control of cytokine gene expression by group $\mathrm{H}$. Group $\mathrm{F}$ recipients achieved less control than groups $\mathrm{D}$ and $\mathrm{H}$.

long term. Blood $(p=0.000023,0.000748$, and $0.003057)$ and graft $(p=0.000776,0.002512$, and 0.019365 ) cyclosporine concentrations of group $\mathrm{H}$ recipients differed significantly from those of groups $\mathrm{E}, \mathrm{F}$, and $\mathrm{G}$. In recipients treated with systemic cyclosporine, graft and spleen concentrations were similar $(p=0.259888)$.

Group D and group H recipients revealed similar rejection grades by POD 6 . However, group $\mathrm{H}$, at an $80 \%$ greater dose, exhibited blood $(p=0.000378)$ and tissue $(p=0.002044)$ cyclosporine levels that were significantly higher and a low pulmonary/blood cyclosporine ratio. Similar tissue cyclosporine concentrations $(p=0.115180)$ were observed between group D and group $\mathrm{F}$ recipients. However, group $\mathrm{F}$ exhibited grade 2 rejection, at a $40 \%$ greater dose, and a low pulmonary/blood cyclosporine ratio. This was reflected in their histologic studies (Fig. 1, C). It appeared that cyclosporine concentrations in blood, rather than graft, closely correlated with the incremental rise in systemic cyclosporine dosing necessary to achieve similar rejection control compared with recipients of aerosol cyclosporine treatment.
RT-PCR: Cytokine gene expression. Evaluation of cytokine gene expression between the control group and groups $\mathrm{D}, \mathrm{F}$, and $\mathrm{H}$ (similar rejection grade vs similar tissue levels to aerosol cyclosporine) by RT-PCR gel electrophoresis is displayed in Fig. 2. Analysis was carried out for IL-6, IL-10, INF- $\gamma$, and iNOS. Aerosol cyclosporine equivalently controlled iNOS gene expression versus systemic therapy (15 $\mathrm{mg} / \mathrm{kg}$ per day) but revealed 20 to 55 times greater IL-6, IL-10, and IFN- $\gamma$ gene expression in the allograft. Group D recipients showed 1.5 to 25 times less cytokine gene expression than group $\mathrm{F}$ animals, which did not have as great an impact on local cytokine attenuation, although dramatic compared with that of control animals. The counts per minute for the measured cytokines on PODs 2, 4, and 6 are displayed in Table II.

\section{Discussion}

The current success of lung transplantation is largely attributed to the effectiveness of immunosuppressive therapy. However, systemic cyclosporine provides inconsistent control, and acute rejec- 
Table II. RT-PCR obtained cytokine $m R N A /$ cyclophilin on PODs 2, 4, and 6 for the various treatment groups

\begin{tabular}{|c|c|c|c|c|c|c|c|c|c|c|c|c|c|c|c|c|}
\hline & \multicolumn{4}{|c|}{ Untreated } & \multicolumn{4}{|c|}{ Aerosol (3 mg/kg) } & \multicolumn{4}{|c|}{ Systemic (5 mg/kg) } & \multicolumn{4}{|c|}{ Systemic $(15 \mathrm{mg} / \mathrm{kg})$} \\
\hline & $P O D$ & 2 & 4 & 6 & $P O D$ & 2 & 4 & 6 & $P O D$ & 2 & 4 & 6 & $P O D$ & 2 & 4 & 6 \\
\hline IL-6 & & 530 & 605 & 1180 & & 215 & 263 & 133 & & 530 & 260 & 267 & & 128 & 18 & 7 \\
\hline IL-10 & & 80 & 115 & 605 & & 68 & 90 & 140 & & 70 & 140 & 248 & & 25 & 22 & 5 \\
\hline IFN- $\gamma$ & & 205 & 290 & 255 & & 58 & 155 & 55 & & 25 & 65 & 80 & & 7 & 3 & 1 \\
\hline iNOS & & 90 & 330 & 735 & & 0 & 10 & 8 & & 60 & 120 & 203 & & 3 & 1 & 7 \\
\hline
\end{tabular}

tion is almost universally predictable after lung transplantation. $^{2}$ Despite enhanced immunosuppression, a subset of patients have refractory acute rejection, and nearly $50 \%$ of lung transplant recipients have obliterative bronchiolitis..$^{5}$ Additionally, the long-term maintenance of systemic immunosuppression has resulted in significant drug-related morbidity. ${ }^{4}$ Increasing experimental evidence suggests that the allograft locally modulates the cellular immune response characteristic of acute rejection. The initial nonspecific inflammatory process gains the specificity of rejection in a supportive allograft environment. ${ }^{22}$ This environment is influenced by immunosuppressive therapy, but systemic immunosuppression incurs a delay in achieving adequate graft levels that allows the destructive cascade to begin. The local delivery of immunosuppressive medications is a potential means to consistently prevent acute rejection and decrease the adverse consequences of systemic immunosuppression.

The early rejection response is characterized by a rapid and aggressive nonspecific inflammatory cell influx responding to the MHC class II surface antigens displayed by passenger leukocytes of the bronchus-associated lymphoid tissue. ${ }^{23}$ The recipient macrophages and leukocytes, responding to foreign antigen, release a variety of proinflammatory cytokines and nitric oxide. Concurrently, the presentation of donor alloantigens to recipient antigen-presenting cells results in the differentiation of Th0 cells into Th1 (cellular) and Th2 (humoral) subpopulations. ${ }^{24}$ IL-2, IL-4, IL-6, IL-10, and IFN- $\gamma$ promote macrophage differentiation, cytotoxic Tlymphocyte production, and the cell surface expression of MHC antigens. The macrophages and cytotoxic T-lymphocytes propagate the acute rejection response by further release of cytokines and nitric oxide. ${ }^{25,26}$ The sponge matrix allograft model demonstrated that the maturation and differentiation of $\mathrm{T}$ cells could occur independently of the host in the proper graft environment. ${ }^{27}$ Furthermore, the intragraft clonal expansion of donor-specific $\mathrm{T}$ and $\mathrm{B}$ cells is significant by 1 week after transplantation ${ }^{24}$ and may be instrumental in the development of chronic rejection. Cyclosporine suppresses $\mathrm{T}$ cell growth factor gene expression by inhibiting IL-2 mRNA transcription. ${ }^{28,29}$ Regional immunotherapy is a logical step in obtaining high local and early drug levels that would inhibit the expression of allograft recognition targets, cytokine release, and effector cell function and migration to the allograft. $^{30}$

Experimental models of heart, liver, and kidney transplantation have repeatedly demonstrated the efficacy of local immunosuppression in controlling acute rejection. Locally perfused budesonide in a rodent heterotopic heart transplant model ${ }^{7}$ resulted in prolonged graft survival, high local drug concentrations, and minimal systemic drug absorption. Systemic administration had no effect at the same dose but had a similar effect when the dose was doubled. Minimal class II MHC antigen expression on donor cells and minimal IL-2 receptor gene expression on graft infiltrating cells indicated that local immunosuppression inhibited donor target recognition molecule expression and recipient effector cell migration and communication within the allograft. ${ }^{30}$ Infusion of intraarterial heparin, prednisolone, mizorubicin, and 6-mercaptopurine ${ }^{9}$ in a canine renal transplant model demonstrated an $80 \%$ increase in local drug concentration and a similar reduction in systemic drug delivery. A tenfold lower drug concentration conferred an antirejection effect equivalent or superior to that of intravenous therapy with less systemic drug exposure. In another model, controlled release by a cyclosporine-impregnated collagen matrix when placed adjacent to the transplanted heart ${ }^{6}$ significantly prolonged allograft survival with negligible systemic tissue concentrations. Others ${ }^{8}$ have used local and systemic cyclosporine pump-based infusion therapy. In a cardiac allograft model, this group found graft survivals of 6.8 days in control animals, 13.6 days in systemically treated animals, and 40.2 days in recipients of local cyclo- 
sporine. A similar dose given intravenously or orally did not realize the same beneficial effect. Regardless of the experimental model these studies have used, cyclosporine concentration measurements have consistently shown that the lung appears to have a particular avidity for cyclosporine.

The effectiveness of aerosolized cyclosporine has been demonstrated previously by our group in animal models. Initial studies in dogs revealed the ability of aerosol cyclosporine to prevent or reduce acute pulmonary rejection with high local cyclosporine concentrations and low systemic drug delivery. ${ }^{10}$ Follow-up studies in the rodent model ${ }^{11,12}$ indicated that the local delivery of aerosol cyclosporine was superior to the systemic route in preventing rejection with significantly lower systemic cyclosporine delivery. Recently, a more efficient and clinically reflective aerosol delivery system has been constructed, and the calculated intrapulmonary deposition of cyclosporine by aerosol inhalation in rodents has been altered. We sought to determine the effectiveness of aerosol cyclosporine monotherapy in controlling acute rejection with high local levels and low systemic drug delivery. Additionally, with the ability of molecular techniques to measure allograft cytokine activity, the effect of aerosol cyclosporine on acute rejection at the molecular level could be determined.

In this study, we convincingly demonstrate that aerosol cyclosporine as locoregional immunotherapy can dose dependently prevent acute rejection in a fully allogeneic rodent lung transplant model. An aerosol cyclosporine dose of $3 \mathrm{mg} / \mathrm{kg}$ per day resulted in grade 1 rejection and was equivalent or superior to that of systemic cyclosporine administration. An $80 \%$ greater systemic cyclosporine dose (15 $\mathrm{mg} / \mathrm{kg}$ per day) also resulted in grade 1 rejection, but at significantly higher blood and graft concentrations than in the aerosol cyclosporine group. A 40\% greater systemic cyclosporine dose $(5 \mathrm{mg} / \mathrm{kg}$ per day) resulted in similar graft concentrations to the most effective aerosol cyclosporine group, but rejection (grade 2) was incompletely controlled. Trough tissue levels in the allograft after aerosol therapy were lower than with systemic therapy, yet rejection was better controlled. The superior control of rejection by aerosol cyclosporine may be due in part to the higher "peak" concentrations of cyclosporine achieved and the higher pulmonary/blood ratios observed in these recipients. Follow-up pharmacokinetic studies of aerosol cyclosporine are warranted. Additionally, the intrapulmonary distribu- tion of aerosol cyclosporine, with its consequent impact on rejection and inflammatory cytokine production, may provide important information regarding the potent effect of minute aerosol cyclosporine doses on the prevention of acute rejection. Systemic absorption of cyclosporine is low when administered locally, probably at levels that do not significantly influence control of rejection or cause toxicity. We have demonstrated that aerosol cyclosporine effectively controlled gene expression of proinflammatory cytokines IL-6, IL-10, IFN- $\gamma$, and iNOS in the allograft. High-dose systemic cyclosporine (15 $\mathrm{mg} / \mathrm{kg}$ per day) achieved better cytokine control than aerosol cyclosporine, but at the cost of extremely high blood and tissue cyclosporine concentrations. A systemically administered dose $(5 \mathrm{mg} / \mathrm{kg}$ per day) with similar tissue levels did not adequately control cytokine gene expression, which was reflected in a higher rejection grade.

In summary, we have demonstrated that aerosol cyclosporine as local immunotherapy prevents acute pulmonary rejection, achieves effective allograft cyclosporine concentrations with low systemic drug delivery, and locally attenuates the production of the proinflammatory cytokines known to be instrumental in the acute rejection response. If the utility and efficacy of aerosol cyclosporine in preventing chronic rejection can be demonstrated, the impact on clinical lung transplantation would be significant.

We gratefully acknowledge the expert technical assistance of Natalya Subbotina, MS (high-pressure liquid chromatography assays), Edward B. Barr, MS, and Bruce A. Muggenberg, DVM (ITRI, aerosol equipment).

REFERENCES

1. Davis RD, Pasque MK. Pulmonary transplantation. Ann Surg 1995;221:14-28.

2. Griffith BP, Hardesty RL, Armitage JM, et al. Acute rejection of lung allografts with various immunosuppressive protocols. Ann Thorac Surg 1992;54:846-51.

3. Trulock EP. Management of lung transplant rejection. Chest 1993;103:1566-76.

4. Griffith BP, Hardesty RL, Armitage JM, et al. A decade of lung transplantation. Ann Surg 1993;218:310-20.

5. Bando K, Paradis I, Similo S, et al. Obliterative bronchiolitis after lung and heart-lung transplantation: an analysis of risk factors and management. J Thorac Cardiovasc Surg 1995; 110:4-14.

6. Bolling S, Lin H, Sintov A, et al. Local immunosuppression of cardiac transplants in rats enhances survival. J Heart Transplant 1990;9:74.

7. Ruers TJM, Buurman WA, Van der Linden CJ. Graft rejection can be treated effectively by local immunosuppression. Transplant Proc 1989;21:1127-9.

8. Stepkowski SM, Goto S, Ito T, et al. Prolongation of heter- 
otopic heart allograft survival by local delivery of continuous low-dose cyclosporine therapy. Transplantation 1989;47:1723.

9. Gruber SA, Canafax DM, Cipolle RJ, et al. Local immunosuppression of the vascularized graft. Surgery 1990;107:20914

10. Dowling RD, Zenati M, Burckart GJ, et al. Aerosolized cyclosporine as single agent immunotherapy in canine lung allografts. Surgery 1990;108:198-205.

11. Zenati M, Duncan AJ, Burckart GJ, et al. Immunosuppression with aerosolized cyclosporine for prevention of lung rejection in a rat model. Eur J Cardiothorac Surg 1991;5:26672 .

12. Keenan RJ, Duncan AJ, Yousem SA, et al. Improved immunosuppression with aerosolized cyclosporine in experimental pulmonary transplantation. Transplantation 1992;53: 20-5.

13. Gill T, Kunz H, Misra D, Hassett A. The major histocompatibility complex of the rat. Transplantation 1987;43:773-8.

14. Mizuta T, Kawaguchi A, Nakahara K, Kawashima Y. Simplified rat lung transplantation using a cuff technique. J Thorac Cardiovasc Surg 1989;97:578-81.

15. Wong KL, Alarie Y. A method for repeated evaluation of pulmonary performance in unanesthetized, unrestrained Guinea pigs and its application to detect effects of sulfuric acid mist inhalation. Toxicol Appl Pharmacol 1982;63:72-90.

16. Raabe OS. Deposition and clearance of inhaled aerosols. In: Witschi H, Nettesheim P, editors. Mechanisms in respiratory toxicology. Boca Raton (FL): CRC Press; 1982. p. 27-76.

17. Yousem SA, Berry GJ, Cagle PT, et al. Revision of the 1990 working formulation for the classification of pulmonary allograft rejection: lung rejection study group. J Heart Lung Transplant 1996;15:1-15.

18. Sawchuk RJ, Cartier LL. Liquid-chromatographic determination of Cyclosporine-A in blood and plasma. Clin Chem 1981;27:1368-73.

19. Gilliland G, Perrin S, Blanchard K, Bunn HF. Analysis of cytokine mRNA and DNA: detection and quantitation by competitive polymerase chain reaction. Proc Natl Acad Sci U S A 1990;87:2725-9.

20. Mattsson P, Zeevi A, Cai J, et al. Effect of aminoguanidine and cyclosporine on lung allograft rejection. Ann Thorac Surg 1996;62:207-12.

21. Kumar MSA, White AG, Alex G, et al. Correlation of blood levels of cyclosporine with the histologic features of cyclosporine toxicity. Transplant Proc 1988;20:407-11.

22. Hayry P, Renkonen R, Leszczynski D, et al. Local events in graft rejection. Transplant Proc 1989;21:3716-20.

23. Prop J, Wildevuur CRH, Nieuwenhuis P. Lung allograft rejection in the rat. II. Specific immunological properties of lung grafts. Transplantation 1985;40:126-31.

24. Hanto DW, Hopt UT, Hoffman RA, Simmons RL. Lymphocyte recruitment, regional blood flow, and vascular permeability at sites of allogeneic cellular interactions. J Immunol 1982;12:2437-41.

25. Ford HR, Hoffman RA, Tweardy DJ, et al. Evidence that production of interleukin- 6 within the rejecting allograft coincides with cytotoxic T lymphocyte development. Transplantation 1991;51:656-61.

26. Zuo XJ, Matsumura Y, Prehn J, et al. Cytokine gene expression in rejecting and tolerant rat lung allograft models: analysis by RT-PCR. Transplant Immunol 1995;3:151-61.
27. Ascher NL, Chen S, Hoffman RA, Simmons RL. Maturation of cytotoxic T cells within sponge matrix allograft. J Immunol 1983;131:617-21.

28. Kronke M, Leonard WJ, Depper JM, et al. Cyclosporin A inhibits T-cell growth factor gene expression at the level of mRNA transcription. Proc Natl Acad Sci U S A 1984;81: 5214.

29. Worrall NK, Lazenby WD, Misko TP, et al. Modulation of in-vivo alloreactivity by inhibition of inducible nitric oxide synthase. J Exp Med 1995;181:63-70.

30. Ruers TJM, Buurman WAA, Van der Linden CJ, Kootstra G. Local inhibition of major histocompatibility complex II induction within the graft: an effective way to induce immunosuppression. Transplant Proc 1987;19:246-8.

\section{Discussion}

Dr. Nasser K. Altorki (New York, N.Y.). It seems that the aerosolized cyclosporine did not quite eradicate the cytokines as effectively as the $15 \mathrm{mg}$ dose of systemic steroids. Did you evaluate some potential side effects in the treated animals with the higher dose of systemic versus the aerosolized component?

Dr. Mitruka. Thank you, Dr. Altorki. There were no directly observed side effects in either group of treatment recipients in this short-term model of lung transplantation. The literature is replete with information regarding systemically administered cyclosporine with chronically maintained blood levels in the $3000 \mathrm{ng} / \mathrm{mg}$ range. After 45 to 60 days of persistently elevated levels, nephrotoxicity and hepatotoxicity are observed. No data are currently available regarding the toxicity of long-term aerosolized cyclosporine. We did not actually measure renal or hepatic levels of cyclosporine, despite the elevated tissue and blood levels, because we did not expect to observe significant toxicity in this 6-day acute rejection mode.

Dr. Chi-Ming Wei (Baltimore, Md.). Do you have data for endothelial nitric oxide synthase (eNOS) expression, nitrate level, and cyclic guanosine monophosphate concentration?

Dr. Mitruka. Thank you, Dr. Wei, for your insightful question. There are many forms of NOS, including inducible and constitutive. The inflammatory process that characterizes early acute rejection is mediated predominantly by the inducible isoform of NOS. We therefore measured iNOS by the PCR as a means to determine the amount of nitric oxide being produced after treatment of the recipient with cyclosporine. We did not measure direct nitric oxide metabolites such as nitrate or nitrite levels, nor did we specifically measure eNOS or cyclic guanosine monophosphate. We have been interested in measuring endothelial cell activation by immunohistochemistry for the intercellular and endothelial cell leukocyte adhesion molecules, and those studies are planned for the near future.

Dr. William A. Cook (North Andover, Mass.). A number of years ago when we were doing some work with microcirculatory studies of acute rejection and observing what was going on inside the vessels, a lot of what we saw was apparent red cell clumping around white cells. These clumps were plugging up the smaller capillaries. It would seem to me that an aerosol treatment would not get to affect that particular part of the hyperacute rejection syndrome. Would it be interesting for you to add another 
cohort to your experimental study, which would give some cyclosporine systemically and some with aerosol and see if your total achieved effect is not better?

Dr. Mitruka. Thank you, Dr. Cook, for that interesting suggestion. We have considered combined therapy with aerosol and systemic cyclosporine in this model but have not explored it further at this early juncture, merely because we wanted to determine the isolated effect of aerosol monotherapy in controlling rejection.

Early deposition studies performed by Dr. Dowling, and by our collaborators in Albuquerque, have actually indicated that aerosol cyclosporine is deposited in all lung fields and in the proximal and distal airways of the rodent after lung transplantation. Although you are certainly correct that the early changes of acute rejection consist of vascular occlusion and direct parenchymal damage, based on our cytokine analysis, aerosol cyclosporine actually seems to diminish the early activation of the inflammatory cells that are directly responsible for the immediate damage.

Dr. Robert D. Dowling (Louisville, Ky.). You described a $3 \mathrm{mg}$ aerosolized dose. Was that the dose that you aerosolized or the dose that the animals received?
Dr. Mitruka. The $3 \mathrm{mg} / \mathrm{kg}$ per day dose of aerosolized cyclosporine represented the target dose that was aerosolized and delivered to the animals. The actual intrapulmonary deposition of cyclosporine was calculated on the basis of a consideration of the animal's weight, minute ventilation, and the anticipated efficiency of deposition. Rodents weighing 250 gm received 0.75 actual milligrams of cyclosporine per day per exposure.

Dr. Dowling. I think that is an important point. This difference in the dose received between the group treated with systemic cyclosporine and the group treated with aerosolized cyclosporine is even more apparent when you look at actually how much of the aerosolized drug the animals received versus how much was aerosolized but not inhaled.

Dr. Mitruka. That is an excellent point that may not be readily apparent. The equivalently effective systemic dose to result in a rejection grade of 1 required 15 $\mathrm{mg} / \mathrm{kg}$ per day or $3.75 \mathrm{mg}$ per animal per day of systemic cyclosporine, which was $80 \%$ higher than the aerosol cyclosporine dose of $3 \mathrm{mg} / \mathrm{kg}$ per day or $0.75 \mathrm{mg}$ per animal per day. 